\title{
Гиобальный рынок
}

\section{катастрофного финансирования и перспективы его формирования B PФ}

\author{
Наталья Александровна Хуторова \\ E-mail: khutorova-na@ranepa.ru, ORCID: 0000-0002-2123-4573 \\ Российская академия народного хозяйства и государственной службы \\ при Президенте РФ, Москва 119571, Российская Федерация
}

\begin{abstract}
Аннотация
Статья посвящена вопросам развития инструментов катастрофного финансирования. ПровеАен анализ состояния глобального рынка катастрофного финансирования с целью выявления основных тенАенций развития и возможностей использования концептуальных поАхоАОв в российской практике финансового рынка. Аоказано, что развитие рынка катастрофного финансирования имеет перспективы в условиях перманентной нестабильности, так как катастрофные бонды уникальны и имеют высокую привлекательность за счет отсутствия корреляции с макроэкономическими событиями. Предположено, что облигации катастроф можно рассматривать в контексте развития устойчивых финансов.

В работе выявлены основные проблемы торможения развития Аанного сегмента рынка в России и сформулированы преАложения, направленные на развитие рынка секьюритизированных инструментов страхования в РФ. Так, отмечена потребность введения в российское правовое поле термина, определяющего категорию ценной бумаги, связанной со страхованием (ILS), и проработка вопросов налогообложения дохода, полученного по данным инструментам. Высказано преАложение о регистрации специализированных проектных компаний (SPV) и катастрофных фондов в российских специальных административных районах. Аналогом катастрофных фондов в России могут стать ЗПИФ с высоким порогом входа Аля квалифицированных инвесторов. В целях проработки вопросов моделирования выпусков облигаций катастроф отмечена необходимость актуализации формулы расчета формирования и порядка использования резервных фондов в субъектах РФ на покрытие расходов в случае стихийных беАствий, в том числе с использованием инструментов катастрофного финансирования. ПреАлагается пилотный выпуск облигаций катастроф от лица ВЭБ РФ в качестве спонсора облигаций в интересах республик и краев, подверженных высоким стихийным рискам. При моделировании пилотных проспектов эмиссии облигаций катастроф преАложено использовать подходы эмиссии структурных облигаций с элементами субординированной облигации. В процессе формирования практики социально ответственных инвесторов и инструментов социально ответственных инвестиций преАложено созАать российский “Зеленый индекс", а также разработать проспект зеленых биржевых фондов (Exchange Traded Funds, ETF). При принятии решения о выпуске облигаций катастроф рекомендуется использовать поАходы Аью-Аилидженс.
\end{abstract}

Ключевые слова: облигации катастроф, стихийные риски, катастрофное финансирование, секьюритизированные активы, страхование

JEL: G10, G18

Аля цитирования: Хуторова Н. А. ГАобальный рынок катастрофного финансирования и перспективы его формирования в РФ // Финансовый журнал. 2021. Т. 13. № 1. С. 75-92. DOI: 10.31107/2075-1990-2021-1-75-92.

(C) Хуторова Н. А., 2021 
https://doi.org/10.31107/2075-1990-2021-1-75-92

\title{
Global Catastrophe Bond Market and the Prospects of Its Formation in the Russian Federation
}

\author{
Natalya A. Khutorova \\ Russian Presidential Academy of National Economy and Public Administration (RANEPA), Moscow \\ 119571, Russian Federation \\ khutorova-na@ranepa.ru, https://orcid.org/0000-0002-2123-4573
}

\begin{abstract}
The article is devoted to the development of instruments for catastrophe risk financing. The state of the global market for disaster risk financing is analyzed in order to identify the main development trends and the possibilities of using conceptual approaches in the Russian practice of the financial market. It is proven that the development of the catastrophe bond market has prospects in conditions of permanent instability, since catastrophe bonds are unique and highly attractive due to the lack of correlation with macroeconomic events. It is suggested that the instruments of catastrophe risk financing can be considered in the context of the development of sustainable finance.

The paper identifies the main problems slowing down the development of the Russian catastrophe bond market, and formulates proposals aimed at developing the market for insurance-linked securities (ILS) in the Russian Federation.

Pilot CAT bonds emission prospectuses should be based on structured bonds, with elements of a subordinated bond. There is a need to introduce into the Russian legal field a term defining ILS as a category. It is proposed to register special purpose vehicles (SPVs) and catastrophe funds in Russian offshores. The Russian analogue of catastrophe funds should be a closed-end investment fund with high funding for qualified investors.

It is proposed to update the formula for calculating the creation of and the procedure for using reserve funds, in particular with the use of catastrophe risk financing tools. A pilot issue of CAT bonds is proposed to be conducted on behalf of VEB.RF, as bonds sponsoring regions exposed to high natural risks. In the process of developing socially responsible investor practice and tools for socially responsible investments, it is suggested to establish a Russian "Green Index" and to create green ETFS in Russia. Due diligence (DD) approaches are recommended for decisions on issuing catastrophe bonds.
\end{abstract}

Keywords: CAT bonds, ILS, financial markets, catastrophe risk financing, risks

JEL: G10, G18

For citation: Khutorova N.A. Global Catastrophe Bond Market and the Prospects of Its Formation in the Russian Federation. Financial Journal, 2021, vol. 13, no. 1, pp. 75-92 (In Russ.). DOI: 10.31107/ 2075-1990-2021-1-75-92.

(c) Khutorova N.A., 2021

\section{BВЕАЕНИЕ}

Глобальный кризис, вызванный пандемией COVID-19 в 2020 г., стал серьезным испытанием Аля мировой экономики и финансовых рынков. В мировом сообществе происходит серьезное переосмысление новых видов рисков и методов их хеАжирования. Уже на протяжении нескольких десятилетий международные организации и национальные регуляторы уделяют все большее внимание проблемам изменения климата, моделированию стихийных рисков и оценке их влияния на национальную и мировую экономику ${ }^{1}$.

1 Task Force on Climate Related Financial Disclosures / TCFD. URL: https://assets.bbhub.io/company/sites/ 60/2020/10/FINAL-2017-TCFD-Report-11052018.pdf. 
Ежегодно происходит большое число природных катаклизмов и техногенных происшествий, убытки от которых традиционно разделяют собственники, страховые компании и официальные власти, что в случае серьезных катастроф существенно отягощает государственные и региональные бюАжеты и заставляет искать новые модели взаимодействия с финансовыми рынками². В 2017-2019 гг. сумма общих экономических потерь из-за природных и техногенных катастроф колебалась в пределах 165-350 млрА Аомл. США, медиана за последние десять лет составила около 220 млрА Аомл. США в гоА, или 0,28 \% мирового ВВП. 2019 г. принес около 140 млрА Аол^. США потерь (0,19 \% совокупного мирового ВВП), из которых только 56 млрА АОлм. США были покрыты страхованием и перестрахованием [Bevere L. et al., 2019].

Вопросы расширения возможностей секьюритизации страховых рисков стали весьма актуальной темой исследований российских и зарубежных ученых и нашли отражение в ряде работ. В то же время остается еще много неизученных проблем и перспективных направлений развития, что порождает интерес к этой теме. Целью исследования стал обзор современного состояния глобального рынка облигаций катастроф Аля определения возможностей использования Аанного инструмента в российской практике.

В странах с развитыми финансовыми рынками уже сформирована концепция устойчивого развития, гАе значимая роль отводится социально ответственным инвестициям. Приобрели популярность устойчивые финансы, разнообразие которых постоянно расширяется и усложняется их профиль [Яковлев И. А., Кабир ^. С., 2018]. Особый интерес представляет рынок секьюритизированных страховых инструментов (insurance-linked securities, ILS), частью которого является рынок облигаций катастроф (cat bonds), которые в современных условиях рассматриваются как эффективный инструмент хеАжирования природных климатических и техногенных рисков и способ секьюритизации страховых рисков [Blanchet J. H. et al., 2017]. Учитывая, что целью облигаций катастроф является сглаживание негативных последствий экологических или техногенных катаклизмов, считаем возможным рассматривать такие облигации инструментами устойчивого развития и отдельным сегментом рынка устойчивых финансов [MSCl, 2020].

Облигации катастроф обращаются на финансовых рынках уже почти 30 лет, с 1992 г., когАа ураган "ЭнАрю" в США нанес существенный урон, что породило на тот момент финансовую инновацию в виле облигаций катастроф. Первый успешный выпуск таких облигаций был осуществлен компанией Hannover Re на 85 млн Аомл. США в 1994 г., с тех пор этот рынок постоянно растет и усложняется ${ }^{3}$. Так, к 2020 г. объем рынка ILS превысил рекордное значение 100 млрА Аомл. США, гАе с кажАым годом возрастает Аоля облигаций катастроф. За последние Аесять лет объемы накопленной эмиссии катастрофных бондов на глобальных рынках утроились, и к концу 2020 г. превысили 44,8 млрА Аом^. США⿱4 . По Аанным Artemis, представленным в отчете за IV кв. 2020 г. о состоянии рынка облигаций катастроф, виАно, что, несмотря на кризисные явления, вызвавшие высокую волатильность и неопределенность на финансовых рынках, и драматическое развитие пандемии COVID-19, объем новых эмиссий устойчиво растет, все объявленные сделки завершены, а объемы эмиссии оставались на уровне Аесятилетнего среднего показателя 5 .

Облигация катастроф (act of god bonds, cat bonds) - это синтетический индуцированный финансовый инструмент, преАставляющий собой некий гибриА межАу страховкой

\footnotetext{
2 The Global Risks Report 2020 / World Economic Forum, in partnership with Marsh \& McLennan companies and Zurich Insurance Group.

3 History-of-CAT-bonds. URL: http://en.entropics.se/cat-bonds/the-history-of-cat-bonds.

4 The Artemis Q4 2020 Catastrophe Bond and Insurance Linked Securities (ILS) / Market Report. URL: https://www.artemis.bm/artemis-ils-market-reports/; Sheehan M. Total cat bond issuance surpasses \$100bn: Aon Securities 2020. URL: https://www.reinsurancene.ws/total-cat-bond-issuance-surpasses-100bn-aon-securities/.

5 The Artemis Q4 2020 Catastrophe Bond and Insurance Linked Securities (ILS) / Market Report.
} 
и облигацией. Фактически имеет место выпуск облигаций, которые работают как страховой полис. По своей сути это дериватив, базисом которого становится событие (триггер). Триггеры, инициирующие выплаты в рамках обязательств по этим займам, могут состоять мибо в общем ущербе от отАельных природных или техногенных катастроф и пандемий в определенный периоА, в определенном месте, либо в масштабах природной катастрофы, измеряемых по заранее установленным правилам. Постоянно расширяется список рисков, убытки по которым будут покрываться за счет облигаций катастроф, также растет количество триггеров по Аанным бумагам. Так, выплаты по облигациям катастроф уже покрывают риски пандемий, кибератак, террористических атак, и даже проектируются выпуски с риском "локдаун" [Хуторова Н. А., 2010; Хуторова Н. А., 2020].

В настоящее время в научной и практической митературе существует многообразие названий Аанных инструментов, среди которых в качестве синонимов используются "облигации катастроф", "катастрофные бонды" или cat bonds. В соответствии с международной практикой облигации катастроф - это структурированный продукт со сложным профилем риска, Аоступ к которым имеют только квалифицированные инвесторы. Чаще всего такого рода инвесторами выступают специализированные фонды катастроф, хеАжевые или взаимные фонды, традиционно формирующие свои портфели из рискованных и высокодоходных бумаг. Облигации катастроф являются АиквиАными, высокодоходными и рисковыми активами, обращающимися как на бирже, так и на внебиржевом рынке.

Обычно спонсорами облигаций катастроф выступают крупные инвестиционные банки или перестраховочные компании в целях привлечения капитала, предназначенного Аля возмещения убытков клиентов по наступившим страховым случаям. Аля выпуска облигаций чаще всего создаются специальные юридические лица (SPV ияи SPI) ${ }^{6}$, которые непосреАственно и выступают эмитентами. В послеАние годы созданы успешные прецеденты, когАа эмитентом выступают международные организации или правительства государств [Васа А., Jain A., 2018]. Основным преимуществом Аля эмитентов облигаций катастроф является низкая стоимость выпуска и обслуживания по сравнению с традиционным страхованием. Выгодоприобретателями выступают государства, органы власти или компании, которые ведут свою Аеятельность в условиях высоких природных, техногенных или пандемических рисков.

Процесс выпуска инициируется страховщиком и состоит из нескольких этапов.

1. Страховщик (перестраховщик) или инвестиционный банк, выступая в роли спонсора (sponsor), создает специального финансового посредника (SPV (SPI)), которому впослеАствии и передает страховые риски в процессе секьюритизации.

2. Спонсор на основании договора перестрахования с SPV выплачивает перестраховочную премию, а SPV обеспечивает страховое покрытие конкретного страхового портфеля по рискам, прописанным в облигации катастроф.

3. SPV осуществляет эмиссию чаще всего среднесрочных облигаций катастроф (cat bonds), в процессе чего происходит передача риска инвесторам.

4. SPV формирует портфель первоклассных высоколиквидных облигаций за счет среАств, полученных от продажи облигаций катастроф.

5. В процессе обращения облигаций катастроф SPV регулярно выплачивает инвесторам купон, размер которого складывается из доходности по приобретенным ценным бумагам и перестраховочной премии. Ао тех пор пока не наступило страховое событие, облигации катастроф работают как обычные облигации: по ним регулярно выплачиваются купоны и в конце срока действия погашается номинал. Ситуация кардинально меняется в случае наступления страхового события - инвесторы могут понести убытки, это может быть часть или весь номинал в размере страховых выплат по наступившему страховому

6 Special Purpose Vehicle и Special Purpose Issuer - специализированный эмитент секьюритизированных страховых инструментов. 
случаю [Володин С. Н., Мистрюков Ю. С., 2018; Огорелкова Н. В., 2016]. Таким образом, очевидно, что данные финансовые инструменты представляют собой Аостаточно рисковый инструмент, вложения в который Аоступны преимущественно квалифицированным инвесторам, и по мере упорядочивания системы регулирования список потенциальных инвесторов постоянно расширяется.

Вопросы хеджирования стихийных рисков нашли отражение в ряде научных работ зарубежных и российских ученых, и к настоящему времени уже наработана значительная теоретическая и практическая база, позволяющая судить о возможности использования облигаций катастроф в процессах управления рисками возникновения убытков в результате стихийных бедствий. Прежде всего необходимо отметить работы зарубежных исслеАователей: монографию A. Braun по вопросам ценообразования на первичных рынках облигаций катастроф [Braun A., 2016], и исследование, посвященное анализу возможностей снижения экстремальных рисков посредством секьюритизации [Blanchet J. et al., 2017], а также работы S. H. Сох с соавторами, в которых систематизированы механизмы секьюритизации рисков и расчета стоимости риска и общих параметров ILS [Cox S. H., Pedersen H. W., 2000; Cox S. H. et al., 2000]. Авторы утвержАают, что ILS являются эффективным инструментом диверсификации рисков, что делает их привлекательными Аля институциональных инвесторов. Особый интерес преАставляют выявленные источники базисного риска и степень его влияния при выборе типов триггеров. Уже более десяти мет вопросы обращения облигаций катастроф находят отражение в работах российских ученых, гАе изучаются возможности Аля использования ILS в России [Суняев А. С., 2015; Токарева Е. А., 2015; Огорелкова Н. В., 2016; Володин С. Н., Мистрюков Ю. С., 2018].

\section{ГАОБААЬНЫЙ РЫНОК КАТАСТРОФНОГО ФИНАНСИРОВАНИЯ}

Аля выявления основных тенденций развития рынка катастрофного финансирования и понимания факторов, на него влияющих, необходимо охарактеризовать структуру основных участников, параметры, определяющие профиль облигаций катастроф, и внешние условия функционирования.

Аанные табл. 1 Аают представление об экономических потерях по различным регионам мира в 2018 г. и степени развитости рынка страхования и перестрахования. Самым развитым регионом является Северная Америка, на Аолю которой приходится 62,5 \% застрахованных убытков по стихийным беАствиям на сумму 52,9 млрА Аолм. США, стремительно растет Аоля стран Азии (24 \%), Аоля же Европы составила всего 9,1 \% совокупного страхового портфеля.

Таблица 1

\section{Экономические потери от природных катастроф по регионам мира в 2018 г. / Number of events, victims, economic and insured losses by region, 2018}

\begin{tabular}{|c|c|c|c|c|c|c|c|}
\hline \multirow[b]{2}{*}{ Регион } & \multirow[b]{2}{*}{$\begin{array}{c}\text { Количество } \\
\text { катастроф }\end{array}$} & \multirow{2}{*}{$\begin{array}{l}\text { Жертвы } \\
\text { (человек) }\end{array}$} & \multirow[b]{2}{*}{$\%$} & \multicolumn{2}{|c|}{ Застрахованные убытки } & \multicolumn{2}{|c|}{ Экономические потери } \\
\hline & & & & $\begin{array}{c}\text { М РА } \\
\text { АОМ. США }\end{array}$ & $\%$ & $\begin{array}{c}\text { М^рА } \\
\text { АО^^. США }\end{array}$ & $\begin{array}{c}\text { \% от мировых } \\
\text { потерь }\end{array}$ \\
\hline Северная Америка & 68 & 329 & 2,4 & 52,9 & 62,5 & 80,5 & 48,8 \\
\hline $\begin{array}{l}\text { ^атинская Америка } \\
\text { и Карибский бассейн }\end{array}$ & 20 & 959 & 7,1 & 1,3 & 1,5 & 4,9 & 2,9 \\
\hline Европа & 44 & 676 & 5,0 & 7,7 & 9,1 & 20,7 & 12,5 \\
\hline Африка & 53 & 2488 & 18,4 & 0,2 & 0,2 & 1,3 & 0,8 \\
\hline Азия & 104 & 8823 & 65,2 & 20,4 & 24,0 & 54,7 & 33,2 \\
\hline Океания и Австралия & 9 & 216 & 1,6 & 1,6 & 1,9 & 2,3 & 1,4 \\
\hline Мировой океан & 6 & 32 & 0,2 & 0,6 & 0,7 & 0,7 & 0,4 \\
\hline Мир всего & 304 & 13523 & 100,0 & 85 & 100,0 & 165 & 100,0 \\
\hline
\end{tabular}

Источник / Source: Swiss Re Institute. Natural catastrophes and man-made disasters in 2018: "secondary" perils on the frontline (https://www.swissre.com/dam/jcr:c37eb0e4-c0b9-4a9f-9954-3dObb4339bfd/sigma2_2019_en.pdf). 
На рис. 1 преАставлены 15 крупнейших эмитентов-спонсоров cat bonds по состоянию на октябрь 2020 г., всего в списке эмитентов насчитывается свыше сотни. Как видно из Аиаграммы, основными спонсорами выступают перестраховочные компании и подразАеления инвестиционных банков. В последние годы активную роль на данном рынке играют международные организации, в первую очередь Всемирный банк в лице МБРР. Так, Всемирный банк начал эмиссию катастрофных бондов в 2014 г., и к 2020 г. накопленная эмиссия превысила 5 м^рА Аолм. СШАㄱ. В арсенале Всемирного банка появляются новые модификации облигаций катастроф, среди них multi-cat bonds. Это разновидность облигации, выплаты по которой предусматривают покрытие рисков стихийных беАствий, наступивших сразу в группе развивающихся стран. Первый выпуск был осуществлен ВБ в 2018 г. и предусматривал выплаты правительствам Чили, Колумбии, Мексике и Перу в случае землетрясений в размере 1,36 млрА Аом.. США⿱ .

\section{5 крупнейших спонсоров облигаций катастроф по величине выпусков, количеству сделок и траншей / Top 15 sponsors of catastrophe bonds by the size of issues, the number of tranche transactions}

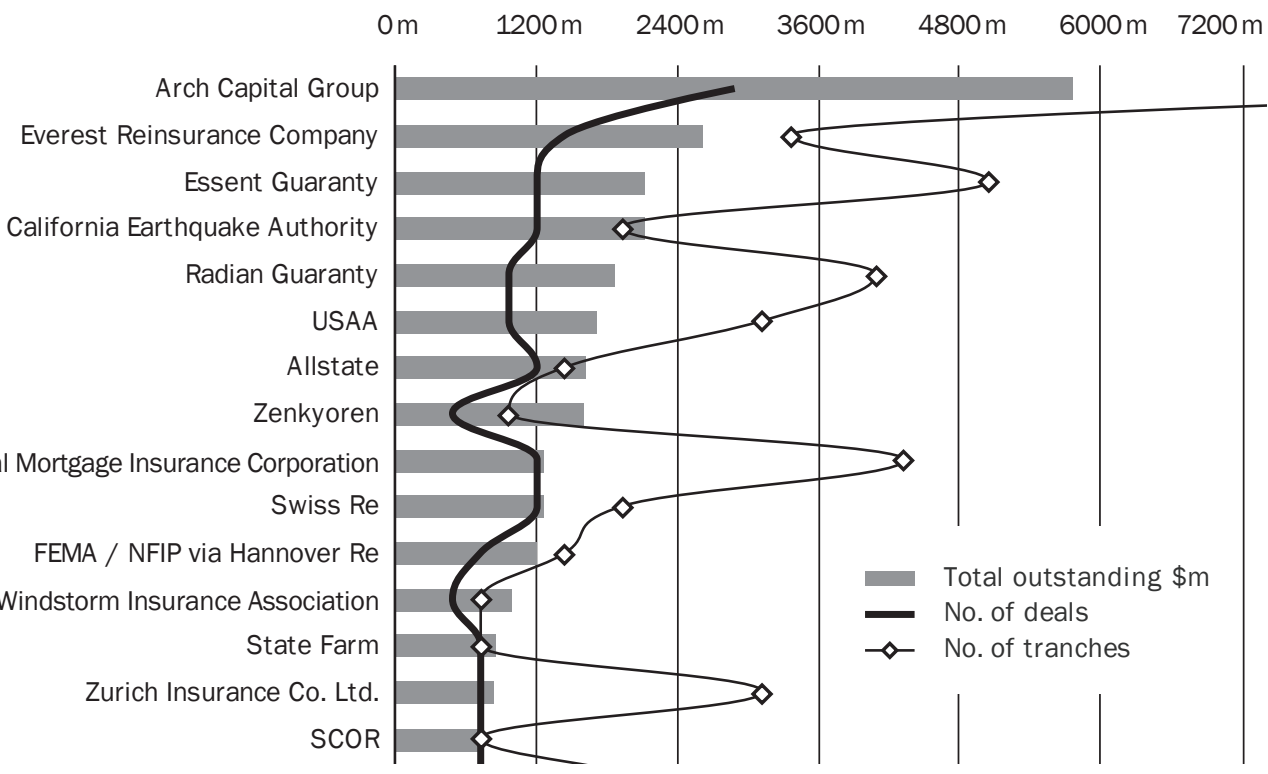

Примечание ред.: по данным на 2.02.2021.

Источник / Source: Artemis (https://www.artemis.bm/dashboard/catastrophe-bonds-ils-outstanding-by-sponsor/).

Аостаточно интересно распределение структуры инвесторов по видам и регионам базирования. Основными инвесторами остаются специализированные фонды катастроф, учрежАенные в США, гАе наиболее развит Аанный сегмент финансового рынка и самые высокие показатели покрытия убытков страхованием. Структура инвесторов на протяжении нескольких лет остается примерно одинаковой, но безусловно высокая волатильность

7 World Bank Treasury and Asia-Pacific Economic Cooperation (APEC) Successfully Conclude First-Ever Catastrophe Bond Workshop / World Bank, 2020. URL: https://www.worldbank.org/en/news/press-release/2020/ 09/24/world-bank-treasury-and-asia-pacific-economic-cooperation-apec-successfully-conclude-first-evercatastrophe-bond-focused-workshop.

${ }^{8}$ https://www.reinsurancene.ws/world-bank-issues-1-36bn-first-ever-multi-country-earthquake-cat-bond/. 
рынков в 2020 г. нашла свое отражение. Важной новацией последних лет стало вк^ючение пенсионных фондов и энАаументов в Аанный список. Это можно объяснить тем, что фактически облигации катастроф преАставляют собой бумаги высокого класса, т. к. их эмитентами являются компании с высокими рейтингами, что и позволяет пенсионным фондам в рамках своих инвестиционных стратегий наполнять ими свои портфели. Аанный аргумент является весьма Аискуссионным, принимая во внимание негативный опыт кризиса 2007-2009 гг., когАа именно проблема искаженной системы рейтингования ценных бумаг стала триггером мирового кризиса. На некоторых биржах в обращении уже есть биржевые фонды ETF на пулы облигаций катастроф, что расширяет круг инвесторов, в том числе и за счет физических лиц с небольшим порогом входа. Как видно из Аанных рис. 2, основными инвесторами остаются фонды катастроф, Аоля которых в 2020 г. составила 74 \%, что на 16 \% больше, чем в 2018 г.; также почти удвоилась Аоля перестраховщиков с 6 до $11 \%$, при этом в 2020 г. хеджевые и взаимные фонды почти втрое сократили долю вложений в облигации катастроф - с 11 до 4 \% [Aon Securities, 2019].

Рисунок 2

Структура инвесторов в облигации катастроф на 30.06.2020, \% / The structure of cat bonds investors by June 30, 2020, \%

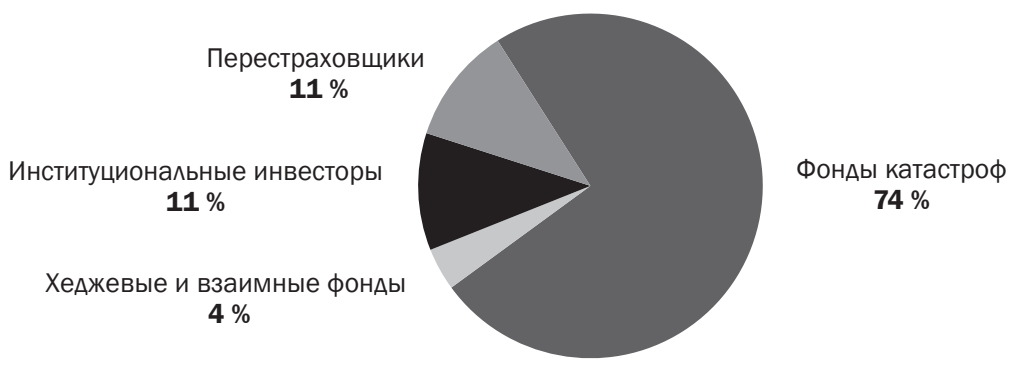

Источник / Source: Artemis (https://www.artemis.bm/artemis-ils-market-reports/).

Основным инвестиционным центром остается Северная Америка с биржей в Чикаго (Chicago Mercantile Exchange, CME), на ее Аолю приходится почти половина рынка и высокоразвитый специализированный центр на Бермудах (Bermuda Stock Exchange, BSX). В последние годы география инвесторов значительно расширилась. Так, например, в 2020 г. по сравнению с 2016 г. Аоля США снизилась с 50 до 46 \% при Авукратном росте Аоли стран Европы (36 \%), гАе основные центры сосреАоточены в Швейцарии, Великобритании и Франции. Традиционным центром базирования инвесторов остаются юрисАикции Бермудов с Аолей 13 \% (против 34,06 \% в 2009 г.). На Аолю Японии приходится около 2 \% ${ }^{9}$. С 2019 г. облигации катастроф Всемирного банка обращаются на бирже в Сингапуре ${ }^{10}$.

Важно отметить, что центральная роль в формировании проспекта эмиссии облигаций катастроф отводится процессам моделирования и прогнозирования катастроф, основанным на объективном распределении вероятностей катастроф и оценки их последствий. Аля этого уточняются виды триггеров по Аанным бумагам, наступление которых и запускает в действие механизм страховой защиты, проводится детальное моделирование ожилаемых расчетных убытков, на основании чего и рассчитывается размер перестраховочной премии и устанавливается величина купона. На рис. 3 представлена диаграмма распределения выпущенных облигаций по видам триггеров.

\footnotetext{
9 Institutional investors grew ILS share, as multi-strategy funds exited / Aon. URL: https://www.artemis.bm/ news/institutional-investors-grew-ils-share-as-multi-strategy-funds-exited-aon/.

${ }^{10}$ Выпуск Аля покрытия рисков от стихийных беАствий на Филиппинах.
} 
Основные виды триггеров и их вес в 2020 г., \% / The main types of triggers and their weight in percentage, 2020

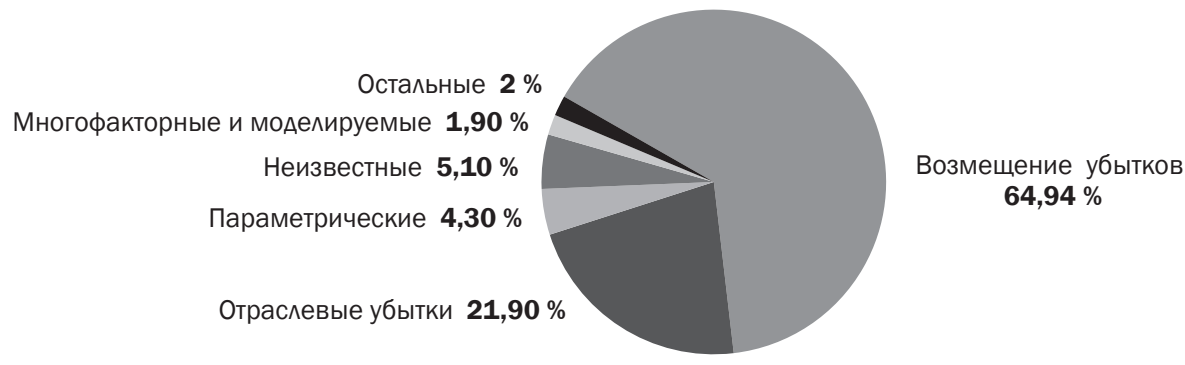

Источник / Source: Artemis (https://www.artemis.bm/artemis-ils-market-reports/).

Основная часть облигаций выпускается с самым простым в расчетах триггером возмещение убытков, Аоля которого в 2020 г. составляет почти 65 \%. Это ситуация, при которой выплаты происходят на основании фактических потерь спонсора, что представляет собой наиболее простой способ, технически аналогичный традиционному договору перестрахования. На Аолю триггера отраслевых потерь приходится почти 22 \%. В этом случае инициирование выплат происходит при условии, что совокупные отраслевые потери от страхового события превышают заранее определенную сумму, а размер выплат зависит от величины застрахованных отраслевых потерь. На Аолю параметрических триггеров приходится чуть больше 4 \%, и их Аоля постоянно растет; это ситуация, при которой выплаты инициируются наступеением и фиксацией определенных событий и метеорологических данных (скорость ветра, сила землетрясения, сила урагана и т. п.), Аанных пандемий (размер вспышки пандемии, скорость роста и распространение вируса через границы) или Аругих физических параметров страхового события. Именно с параметрическими триггерами моделируются все больше выпусков, и такие бумаги преАставляют наибольший интерес Аля инвесторов. События могут быть весьма разнообразны и необычны. В числе триггеров есть "триггеры моделируемых потерь" и "многофакторные триггеры", на их Аолю пока в совокупности приходится всего 2 \% выпусков. Фактически они преАставляют собой результаты построенных моделей катастроф или Аругих неблагоприятных событий на основе исторического опыта с использованием инструментов прогнозирования и моделирования. Выплаты начинаются только в случае, если расчетные потери спонсора после страхового события окажутся выше определенного порогового значения. Также выпускаются облигации с гибридными триггерами, которые основаны на комбинированных подходах (например, объединение триггеров моделируемых и отраслевых потерь в один триггер). КажАый тип триггера имеет свои преимущества и недостатки и по-разному влияет на базисный риск спонсора [Огорелкова Н. В., 2016]. Отметим, что наиболее привлекательным триггером Аля спонсора является самый простой - "возмещение убытков", который не влияет на его базисный риск. В то же время инвестор заинтересован во вложениях с параметрическими и моделируемыми потерями Аля снижения неопределенности. Оптимальный выбор триггера в проспекте эмиссии является весьма сложной задачей, решению которой посвящен рял работ, в первую очередь зарубежных исследователей, среди которых D. Hagedorn и Ар., в которой преАложены алгоритмы выбора оптимального триггера с целью снижения стоимости сделок Аля страховых компаний [D. Hagedorn et al., 2012; Clark S. P. et al., 2016]. Нельзя не согласиться с утверждением Огорелковой Н. В., что в российских условиях при первых выпусках будет преобладать триггер "возмещения убытков", так как он прост в расчетах и использовании и полностью иск^ючает базисный риск Аля спонсора [Огорелкова Н. В., 2016]. 
На рис. 4 представлены кривые распределения средней величины расчетных убытков и средней величины купонов по бумагам, на основании этих Аанных формируется страховой коэффициент, который принимается в расчет спреда по катастрофным бондам. Среднее расчетное значение ожидаемых убытков колеблется в Аиапазоне от 1,8 Ао 3,5 \%, этот показатель рассчитывается при помощи математических моделей и служит отправной точкой в установлении величины купона, Аинамика значений которого преАставлена черной кривой.

Так, например, во II кв. 2020 г. было привлечено 2,56 млрА Аолм. США рискового капитала, гАе ожилаемые расчетные убытки распределены следующим образом: примерно 60 \% выпусков рассчитано на ожилаемые убытки менее $2 \%$; 29 \% выпусков имели ожилаемый убыток от 2,01 до 4 \%, в то время как более 10 \% имели ожилаемый убыток более 4 \%. Облигации Sanders Re II от Allstate отличались самым низким ожиАаемым убытком в размере 0,61 \%, в то время как транш облигаций класса В компании Blue Halo Re oт Allianz характеризовался самым высоким показателем - 5,5\%. B IV кв. 2020 г. был выпущен один транш облигаций компании Res Re c максимальными расчетными ожидаемыми убытками 14,84 \%11.

Рисунок 4

Кривые средней ожидаемых убытков и средней ставки по купонам, \% / Average catastrophe bond \& ILS issuance expected loss and average coupon rate, \% $\%$

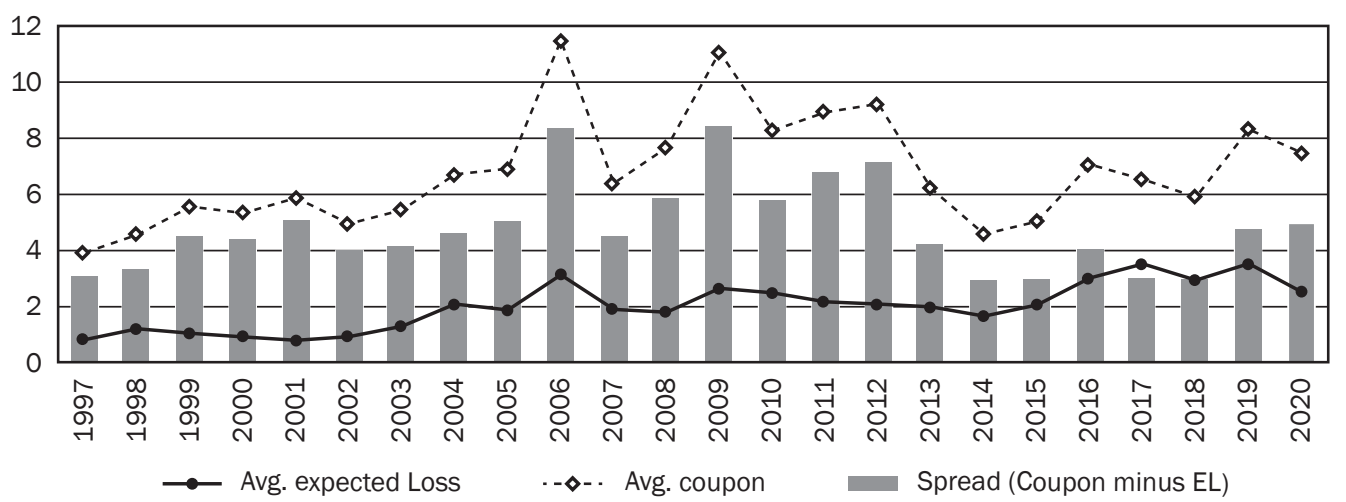

Источник / Source: Artemis (https://www.artemis.bm/dashboard/cat-bonds-ils-expected-loss-coupon/).

Ставка купона формируется из Авух частей - фиксированной и плавающей - и складывается из Аоходности по приобретенным первоклассным бумагам в портфелях SPV и перестраховочной премии, что делает облигации катастроф Аостаточно привлекательными, в то же время сохраняется значительный спреА, около 4,5 \%, между средним значением купона и средним значением ожидаемых убытков.

На рис. 5 представлено распределение в процентном соотношении в выпусках по вемичине купонов по состоянию на август 2020 г. Вопросы ценообразования и адекватности расчета величины купона остаются центральными при формировании рынка облигаций катастроф, что традиционно вызывает интерес у исследователей. Согласимся с авторами статьи, которые утверждают, что риск катастроф не подАается хеджированию традиционными деривативами и требует создания специальных моделей, основанных на временной структуре процентных ставок и безарбитражных операциях [Cox H. S. et al., 2000].

\footnotetext{
${ }^{11}$ Q4 2020 Catastrophe Bond and ILS Market Report / Artemis. URL: https://www.artemis.bm/wp-content/ uploads/2021/01/q4-2020-catastrophe-bond-ils-report.pdf?utm_source=ReportsPage\&utm_medium=Link\&utm_ content=Q42020Report\&utm_campaign=Q42020Report.
} 
Распределение выпусков облигаций катастроф по векичине купонов, \% / Catastrophe bonds \& ILS distribution by coupon pricing, \%

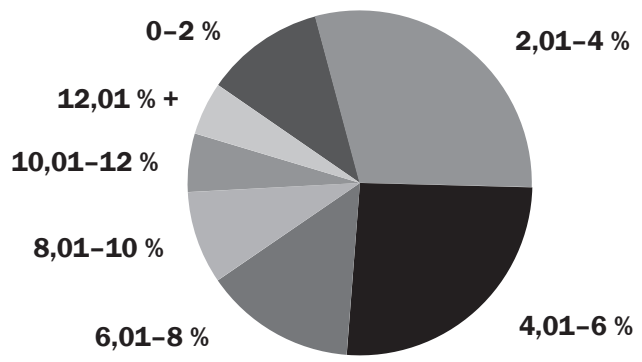

Источник / Source: Artemis (https://www.artemis.bm/dashboard/cat-bonds-ils-by-coupon-pricing/).

Интересен факт того, что в 2020 г. ставки по купонам продолжали расти. Так, всего в обращении, с разбивкой по величине купона: 12 \% выпущенных бумаг имеют купон от 0 до 2 \%, 27,3 \% бумаг - купон в диапазоне от 2 до 4 \%, и только 10,7 \% облигаций катастроф выпущено с купоном в диапазоне от 10 \% и выше (рис. 5). По Аанным Artemis, в III кв. 2020 г. самая низкая ставка по купону в 3,5 \% была предложена по очередному траншу компанией Catahoula Re, а самый высокий купон (16 \%) выплачен компанией Blue Halo Re. B IV кв. 2020 г. самый высокий купон (26 \%) был назначен по первому траншу облигаций компании Res $\operatorname{Re}^{12}$. В целом можно отметить, что ставка купона по таким бондам опреАеляется индивиАуально исходя из построенных сценариев Аля кажАого выпуска. Выпуск часто Аелится на транши, внутри которых могут быть бонды класса А или $\mathrm{B}^{13}$. Так, пандемические бонды Всемирного банка 2017 г. класса А имели купон 6,5 \% + ставка U.S. dollar Libor за 6 мес., в то время как по траншу класса В был объявлен

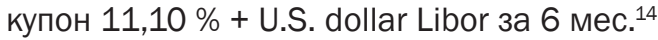

Рисунок 6

\section{Кривая коэффициента (купон / ожидаемые убытки) по облигациям катастроф / Catastrophe bonds \& ILS average multiplier by year}

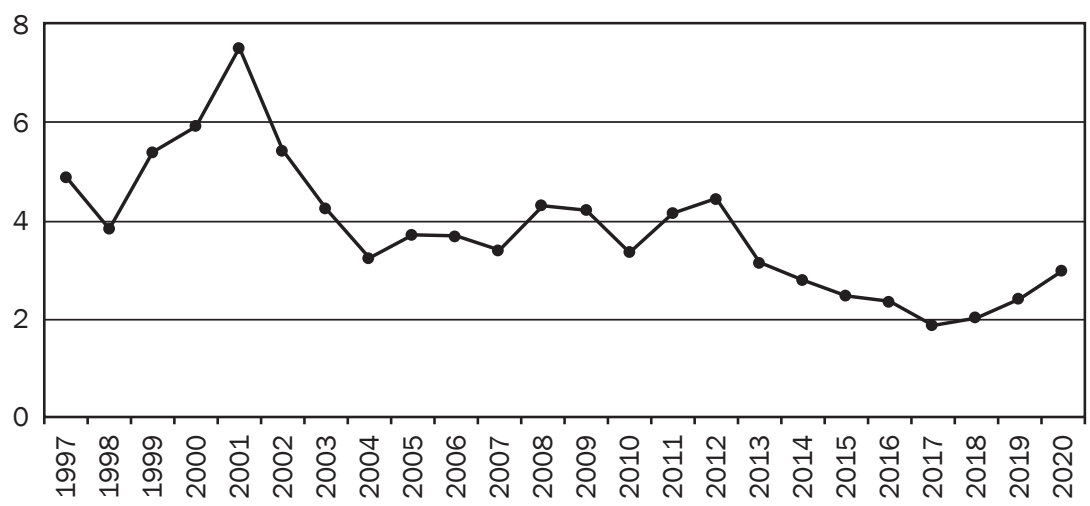

Источник / Source: Artemis (https://www.artemis.bm/dashboard/cat_bonds_ils_average_multiple/).

\footnotetext{
${ }^{12}$ Artemis, Q3, 2020. URL: https://www.artemis.bm/artemis-ils-market-reports.

${ }^{13}$ Выпуски бондов киасса А основаны на меньшем значении ожидаемых потерь и обычно имеют ставку купона ниже по сравнению с бондами класса В.

${ }^{14}$ World Bank Launches First-Ever Pandemic Bonds to Support \$500 Million Pandemic Emergency Financing Facility.
} 
Инвесторы Аля принятия решения по вложениям в первую очередь основываются на значениях коэффициента, определяющего в упрощенном виде уровень привлекательности Аля инвестора. Он рассчитывается как отношение ставки купона к ожидаемым убыткам. Чем ниже значение коэффициента, тем ниже риски по бумаге Аля инвестора. Так, исходя из Аанных графика на рис. 6 видно, что в период роста числа катаклизмов и катастроф возрастает значение коэффициента, что означает рост рисков инвестора. Как видно на рис. 6, рекордным значением остается уровень 2001 г. (7,5), высокие показатели наблюАались в 2008 и в 2012 гг. (4,34 и 4,65 соответственно), самые же низкие значения фиксировались в 2017 и 2018 гг. (2,05 и 2,34 соответственно). В работе S. Clark, M. Dickson и F. R. Neale подтверждена гипотеза, что облигации катастроф благодаря моделируемым рискам могут эффективно использоваться в целях Аиверсификации портфеля [Clark S. et al., 2016]. При проведении сравнительного анализа в части ценообразования и доходности классических высокодоходных корпоративных облигаций и облигаций катастроф (рис. 7) становится очевидным, что динамика спредов по Аанным инструментам на фоне основных событий, влияющих на финансовые рынки, разнонаправленная, а спреды по облигациям катастроф значительно менее волатильны. В то же время среднегодовая Аоходность по таким бумагам с начала 2000-х гг. составила около 8,5 \%, а к 2015 г. превышала $10 \%$, что на уровне низких и даже отрицательных процентных ставок делает доходность сопоставимой с высокорисковыми "мусорными" облигациями, увеличивая привлекательность этих инструментов в процессе формирования сбалансированного портфеля ценных бумаг, в том числе и Аля венчурных инвесторов.

Рисунок 7

\section{Аинамика спредов по облигациям катастроф и по высокодоходным корпоративным облигациям на фоне основных событий, влияющих на финансовые рынки / Dynamics of spreads for catastrophe bonds and high yield corporate bonds in major events affecting financial markets}

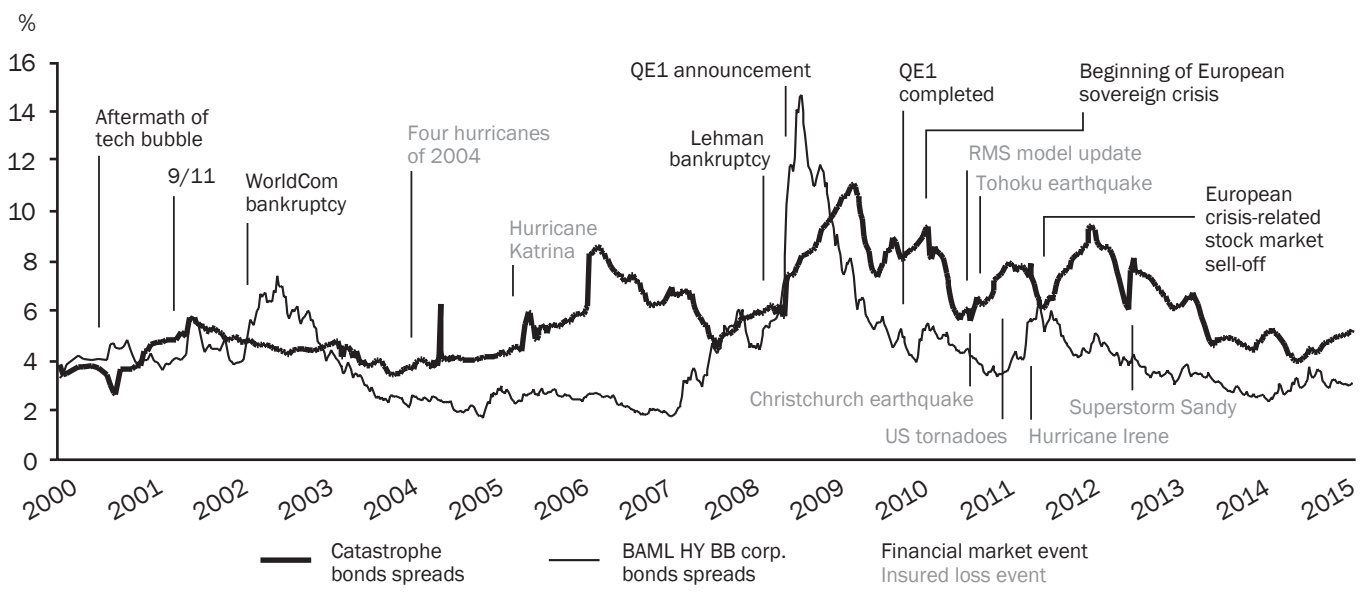

Источник / Source: The Drivers of Catastrophe Bond Pricing, p. 3 (https://www.partnerre.com/assets/uploads/ docs/The-Drivers-of-Catastrophe-Bond-Pricing.pdf).

В целом можно утверждать, что Аля страховых компаний в займах катастроф рисковый профиль может быть более привлекательным по сравнению с традиционными кредитами или эмиссией облигаций [Огорелкова Н. В., 2016; Аyyub B. M. et al., 2016]. По мере снижения вероятности наступления стихийного события растут моделируемые убытки, и, наоборот, при росте вероятности наступления события снижается ожидаемый ущерб и расширяется спектр финансовых инструментов Аля управления рисками катастроф. 
Таким образом, можно резюмировать, что облигации катастроф имеют как ряд преимуществ, так и определенные ограничения (табл. 2), которые в той или иной степени будут проявляться в зависимости от уровня развития финансового и в особенности страхового рынков. Особо стоит отметить, что облигации катастроф незаменимы Аля покрытия реАких рисков с высоким разрушительным воздействием, как, например: землетрясение в Армении в 1988 г., ураган "Катрина" в 2005 г. в США, землетрясение в Японии в 2011 г., тайфун на Филиппинах в 2013 г. и т. п.

Таблица 2

\section{Преимущества и недостатки облигаций катастроф / Advantages and disadvantages of cat bonds}

\begin{tabular}{|c|c|}
\hline Преимущества & $\begin{array}{c}\text { Недостатки } \\
\text { (ограничения) }\end{array}$ \\
\hline $\begin{array}{l}\text { Аия эмитентов (страховщиков) возможность } \\
\text { в Аолгосрочной перспективе покрытия или передачи } \\
\text { рисков с фиксацией премии. } \\
\text { Сроки обращения cat bonds значительно превышают } \\
\text { срок Аоговоров перестрахования с фиксированной } \\
\text { премией }\end{array}$ & $\begin{array}{l}\text { Сложная структура выпуска по сравнению с договором } \\
\text { страхования. } \\
\text { Необходимость созАания SPV и подАержания счетов } \\
\text { обеспечения }\end{array}$ \\
\hline $\begin{array}{l}\text { Гибкое ценообразование и высокая ликвидность } \\
\text { за счет использования принципов синдикации Аля } \\
\text { большого числа глобальных инвесторов. Бумаги } \\
\text { обращаются на бирже, что обеспечивает ликвиАность } \\
\text { и сбалансированный вторичный рынок }\end{array}$ & $\begin{array}{l}\text { Задействовано большее количество сторон; } \\
\text { необходимость заключения специальных соглашений } \\
\text { и проведение экспертиз. Необходимость проведения } \\
\text { процедуры DD (Due diligence) }\end{array}$ \\
\hline $\begin{array}{l}\text { Выгодный профиль кредитного риска. } \\
\text { САелки с полным финансированием, без риска } \\
\text { пропущенных или просроченных платежей }\end{array}$ & $\begin{array}{l}\text { Необходима высокоразвитая инфраструктура } \\
\text { финансового рынка со всеми участниками } \\
\text { (торговые площадки, управляющие, система расчетов } \\
\text { и обеспечения, спец. депозитарий, рейтинговые } \\
\text { агентства) }\end{array}$ \\
\hline \multicolumn{2}{|l|}{$\begin{array}{l}\text { Премии. Размер перестраховочной премии сравним } \\
\text { с обычным (пере)страхованием. } \\
\text { Иск^ючение составляют полярные варианты очень } \\
\text { низких или очень высоких ожидаемых убытков }\end{array}$} \\
\hline $\begin{array}{l}\text { Идеальны Аия покрытия редких рисков с высоким } \\
\text { разрушительным воздействием }\end{array}$ & $\begin{array}{l}\text { Нерентабельны Аля покрытия обычных стихийных } \\
\text { рисков }\end{array}$ \\
\hline
\end{tabular}

Источник: составлено автором на основе [Васа A., Jain A., 2018] / Source: compiled by the author based on the [Baca A., Jain A., 2018].

На основании проведенного анализа современного состояния рынка катастрофного финансирования и опубликованных работ по данной тематике стоит отметить, что в России на современном этапе развития финансовых рынков постепенно зреют предпосылки Аля формирования сегмента катастрофного финансирования, что обусловлено потребностью со стороны как бизнеса, профессионального сообщества, так и органов власти. Тем не менее в России существует рял сложностей, которые тормозят развитие сегмента катастрофного финансирования. Важным фактором торможения появления Аанного инструмента в России является слабость и ограниченность финансового рынка в целом и антироссийские секторальные санкции. Также особо стоит отметить низкие обороты рынка страхования и перестрахования и только еще зарождающуюся модель страхового поведения. В то же время в условиях низких или даже отрицательных ставок растет аппетит к риску, что стимулирует инвестиционные фонды к спросу на новые сложные финансовые инструменты, способные принести сравнительно высокий дохоА. 


\section{ПРОБАЕМЫ И ПЕРСПЕКТИВЫ ФОРМИРОВАНИЯ РЫНКА КАТАСТРОФНОГО ФИНАНСИРОВАНИЯ В РФ}

На основе проведенного критического анализа видится целесообразным сформулировать основной пул проблем, характерных Аля современной России, и преАложить основные направления развития рынка катастрофного финансирования в РФ. Проблемы сосреАоточены в разных плоскостях, основными из которых выделены проблемы правового, экономического, морально-этического и технического (инфраструктурного) характера.

Правовые проблемы. В настоящее время в нашей стране отсутствует законодательная база Аля эмиссии Аанного виАа ценных бумаг, что обусловлено спецификой юридической и экономической трактовки облигации, в соответствии с которой держателю обеспечивается гарантия (право) на получение номинала в установленный срок, в то время как по облигациям катастроф при наступлении страхового случая Аержатель в лучшем случае получит мишь частичную выплату номинала и процентов. В связи с этим видится целесообразным в порядке пилотных выпусков использовать подходы эмиссии структурных облигаций с элементами субординированной облигации. Также назрела необходимость введения в российское правовое поле термина, определяющего категорию ценной бумаги, связанной со страхованием (ILS), и проработки вопросов налогообложения Аохода, полученного по Аанным инструментам. Еще одним стимулом развития рынка катастроф может стать возможность регистрации SPV и катастрофных фондов в российских специальных аАминистративных районах (САР) с гибкими правилами налогового и валютного регулирования ${ }^{15}$. Аналогом катастрофных фондов в России могут стать закрытые паевые инвестиционные фонды (ЗПИФ) с высоким порогом входа Аля квалифицированных инвесторов.

Экономические проблемы. В условиях роста расходов на ликвиАацию послеАствий катастроф различного характера перед региональными властями остро встает проблема Аефицита средств и нехватки сформированных резервов. Традиционные схемы финансирования расходов при наступлении чрезвычайной ситуации не Аают возможности без помощи центра и на Аолжном уровне ликвидировать последствия. Предусмотренные резервные фонды формируются из расчета на душу населения и фактически не учитывают специфику регионов. Также аккумулированные среАства фактически являются зарезервированными и не приносят Аохода. В связи с этим преАставляется целесообразным провести исслеАование при сотрудничестве Минфина и МЧС, позволяющее конкретно в каждом субъекте РФ оценить вероятность реализации чрезвычайных ситуаций, размер ожиАаемых убытков, актуализировать формулу расчета формирования и порядок использования резервных фондов, в том числе с использованием инструментов катастрофного финансирования.

Безусловно, основной проблемой развития рынка катастрофного финансирования в России остается малая глубина финансового рынка и высокая волатильность вслеАствие высоких страновых рисков, что снижает интерес иностранных инвесторов к российским инструментам. В то же время, принимая во внимание опыт Всемирного банка как спонсора multi-cat bonds ${ }^{16}$, перспективным направлением может стать аАаптация опыта ВБ в России в виле пилотного выпуска облигаций катастроф от лица ВЭБ РФ, который выступит как инициатор выпуска облигаций в интересах республик и краев, поАверженных высоким стихийным рискам. Также в рамках развития регионального финансового рынка в ЕАЭС и Аальнейшего наращивания сотрудничества в финансовой сфере со странами АТР спонсором может выступать ЕБР (Евразийский банк развития). Интересным преАставляется конструирование выпусков в форме multi-cat bonds. ОтАельной

\footnotetext{
15 Федеральный закон от 3 августа 2018 г. № 291-Ф3 «О специальных аАминистративных районах на территориях Калининградской области и Приморского края". URL: http://www.consultant.ru/document/cons_doc_ LAW_304082/.

${ }^{16}$ https://www.reinsurancene.ws/world-bank-issues-1-36bn-first-ever-multi-country-earthquake-cat-bond/.
} 
темой изучения остается выбор и расчет триггеров по таким облигациям, которые позволят трансформировать риски и привлечь на рынок перестраховочные компании.

Морально-этические проблемы. В нашей стране еще только формируются робкие практики созАания класса социально ответственных инвесторов и инструментов социально ответственных инвестиций, что пока делает облигации катастроф и другие инструменты устойчивых финансов экзотическими инструментами. Вызывает дискуссии вопрос о том, корректно ли включать облигации катастроф в разряА климатических или "зеленых" финансов. Стоит отметить, что пока в международной практике нет устоявшегося единого стандарта Аля определения "зеленых" финансовых инструментов. Так, в работе Е. П. Федоровой приведены различные трактовки "зеленого" финансирования, и в соответствии с определением рабочей группы G20 по изучению “зеленых" финансов поА таковыми понимают "финансирование инвестиций, которые обеспечивают в широком смысле экологически устойчивое развитие». В таком случае облигации катастроф возможно причислить к категории не только устойчивых, но и "зеленых" инструментов финансирования [Федорова Е. П., 2020]. Отмечается также многообразие устойчивых финансов (направлены на Аостижение целей и задач, определенных концепцией устойчивого развития) и их разновидностей, в частности, климатические финансы определены как "инструменты, направленные на адаптацию к изменению климата" [Яковлев И. А., Кабир ^. С., 2018]. Это также позволяет рассматривать облигации катастроф, в частности пандемические бонды, как инструмент устойчивых и климатических финансов.

В рамках Аанной работы облигации катастроф рассматриваются как инструменты устойчивого финансирования. В связи с этим возможна корреляция с "зелеными" финансами и индексами от них. "Зеленые" индексы, или индексы устойчивого развития, в частности MSCl ACWI Sustainable Impact Index ${ }^{17}$, активно используемые на зарубежных площадках, позволяют адекватно оценить ситуацию на рынке и принять решение при формировании портфелей. В этом направлении полезным инструментом может стать российский "индекс" (Russian Government Bond Index, RGBI), при расчете за пример можно принять семейство индексов S\&P (S\&P Green Bond Index $)^{18}$, при помощи которого социально ответственные инвесторы смогут Аиверсифицировать свои портфели, в том числе с использованием облигаций катастроф. Еще одним перспективным направлением представляется разработка проспектов "зеленых" ETF ${ }^{19}$, в основе которых будут наиболее надежные облигации катастроф, в том числе Всемирного банка, что позволит расширить линейку устойчивых финансов и популяризовать практику социально ответственных инвестиций в России. Стимулом развития Аанного сегмента финансового рынка может стать схема ^ьготного налогообложения Аохода, полученного по инструментам “зеленых" инвестиций и облигациям катастроф, в том числе с использованием в качестве ориентира ключевой ставки Банка России.

Технические. При принятии решения о выпуске облигаций катастроф, и тем более при аргументации решения по инвестированию в данные инструменты, требуется провеАение комплексных исследований, позволяющих аАекватно оценить риски стихийных событий или техногенных катастроф. В связи с этим эффективным методом нам виАится расширение практики проведения процедуры Аью-АилиАженс ${ }^{20}$ в части оценки вероятности наступления внештатной ситуации и ее послеАствий Аля реализуемых крупных проектов

\footnotetext{
${ }^{17}$ https://www.msci.com/msci-acwi-sustainable-impact-index.

${ }^{18}$ S\&P Green Bond Index - индекс бумаг, имеющих социально ответственный профиль. URL: https://www. spglobal.com/spdji/en/indices/fixed-income/sp-green-bond-index/\#overview.

${ }^{19}$ Worth a Look / ETF.com, 2016. URL: https://www.etf.com/sections/index-investor-corner/swedroe-revisedcatastrophe-bonds-worth-look.

${ }^{20}$ Аью-дилиАженс - процедура обеспечения Аолжной Аобросовестности, независимый сбор объективной информации и экспертная оценка сведений об активе с целью защиты собственности, капитала и репутации от вероятного ущерба.
} 
и моделирования стихийных и техногенных рисков с расчетом и присвоением опреАеленных рейтингов, что может лечь в основу проектирования выпусков облигаций.

Аля полноценного функционирования рынка облигаций катастроф необходимо созАать инфраструктуру, вк^ючающую в себя торговую платформу, расчетные организации и обязательно класс специализированных управляющих Аля принятия оправданных решений. Новый профессиональный участник рынка ценных бумаг - инвестиционный консультант ${ }^{21}$ - Аолжен в обязательном порядке владеть знаниями и компетенциями в части эмиссии и обращения инструментов катастрофного финансирования.

Полученные результаты по итогам проведенного анализа позволили систематизировать финансовые инструменты управления стихийными рисками в зависимости от уровня рисков в сводную табл. 3.

Таблица 3

Спектр финансовых инструментов управления стихийными рисками в зависимости от уровня рисков / Range of financial instruments for natural risk management by the risk level

\begin{tabular}{|c|c|c|c|c|}
\hline $\begin{array}{l}\text { Уровень } \\
\text { рисков }\end{array}$ & $\begin{array}{c}\text { Виды } \\
\text { рисков }\end{array}$ & $\begin{array}{c}\text { Финансовые } \\
\text { инструменты } \\
\text { управления } \\
\text { стихийными } \\
\text { рисками }\end{array}$ & $\begin{array}{c}\text { Финансовые } \\
\text { источники } \\
\text { покрытия убытков } \\
\text { от стихийных } \\
\text { бедствий }\end{array}$ & $\begin{array}{c}\text { Перспективные } \\
\text { направления } \\
\text { развития в РФ }\end{array}$ \\
\hline $\begin{array}{l}\text { Релко } \\
\text { реализуемые } \\
\text { риски с высокой } \\
\text { разрушительной } \\
\text { силой }\end{array}$ & $\begin{array}{l}\text { Землетрясения } \\
\text { большой силы, } \\
\text { тропические } \\
\text { штормы, ураганы } \\
\text { с высокой } \\
\text { разрушительной } \\
\text { силой }\end{array}$ & $\begin{array}{l}\text { Облигации } \\
\text { катастроф, } \\
\text { основанные на } \\
\text { параметрических } \\
\text { и моделируемых } \\
\text { триггерах. } \\
\text { Государственные } \\
\text { займы }\end{array}$ & $\begin{array}{l}\text { Средства } \\
\text { национальных } \\
\text { правительств, } \\
\text { международных } \\
\text { организаций } \\
\text { и средства, } \\
\text { аккумулированные } \\
\text { в процессе эмиссии } \\
\text { саt bonds. } \\
\text { Выплаты по } \\
\text { страховым полисам } \\
\text { и договорам } \\
\text { перестрахования }\end{array}$ & $\begin{array}{l}\text { Эмиссия от имени } \\
\text { ВЭБ РФ, Евразийского } \\
\text { банка развития } \\
\text { облигаций катастроф } \\
\text { Аля покрытия убытков } \\
\text { от стихийных событий } \\
\text { чрезвычайной силы } \\
\text { (землетрясения, } \\
\text { пандемия } \\
\text { с карантинными } \\
\text { мерами в масштабах } \\
\text { страны) }\end{array}$ \\
\hline $\begin{array}{l}\text { Риски средней } \\
\text { величины }\end{array}$ & $\begin{array}{l}\text { Землетрясения } \\
\text { силой не выше } \\
5 \text { бамлов, } \\
\text { наводнения } \\
\text { в масштабах } \\
\text { страны, сели, } \\
\text { оползни }\end{array}$ & $\begin{array}{l}\text { Облигации } \\
\text { катастроф } \\
\text { с триггером } \\
\text { “возмещение } \\
\text { убытков", кредитная } \\
\text { миния на покрытие } \\
\text { непредвиденных } \\
\text { расходов }\end{array}$ & $\begin{array}{l}\text { Средства } \\
\text { национальных } \\
\text { правительств, } \\
\text { международных } \\
\text { организаций } \\
\text { и средства, } \\
\text { аккумулированные } \\
\text { в процессе эмиссии } \\
\text { саt bonds. } \\
\text { Выплаты по } \\
\text { страховым полисам } \\
\text { и договорам } \\
\text { перестрахования }\end{array}$ & $\begin{array}{l}\text { Эмиссия облигаций } \\
\text { катастроф от имени } \\
\text { перестраховочных } \\
\text { компаний или } \\
\text { правительств } \\
\text { субъектов РФ } \\
\text { (наводнения } \\
\text { в Тулуне, разлив } \\
\text { нефтепродуктов } \\
\text { в Норильске) }\end{array}$ \\
\hline $\begin{array}{l}\text { Традиционные } \\
\text { стихийные } \\
\text { риски с низким } \\
\text { разрушительным } \\
\text { действием }\end{array}$ & $\begin{array}{l}\text { ^окальные } \\
\text { наводнения } \\
\text { и землетрясения }\end{array}$ & $\begin{array}{l}\text { Страховые полисы } \\
\text { и договоры } \\
\text { перестрахования. } \\
\text { Резервные фонды } \\
\text { на покрытие } \\
\text { непредвиденных } \\
\text { расходов }\end{array}$ & $\begin{array}{l}\text { Резервные фонды } \\
\text { региональных } \\
\text { правительств. } \\
\text { Выплаты по } \\
\text { страховым полисам } \\
\text { и договорам } \\
\text { перестрахования }\end{array}$ & $\begin{array}{l}\text { Страховая защита: } \\
\text { традиционные } \\
\text { и инновационные } \\
\text { страховые полисы }\end{array}$ \\
\hline
\end{tabular}

Источник: составлено автором / Source: compiled by the author.

21 Фелеральный закон от 22.04.1996 № 39-Ф3 (реА. от 31.07.2020) "О рынке ценных бумаг”. Ст. 6.1. Аеятельность по инвестиционному консультированию (введена законом от 20.12.2017 № 397-Ф3). URL: http:// www.consultant.ru/document/cons_doc_LAW_10148/c7375c64b45cadae15697cffbee9601fadc60975/. 


\section{ВЫВОАЫ}

В целом стоит отметить, что мировая практика обращения инструментов катастрофного финансирования Аоказала эффективность такого рода инструментов. Расширяется список спонсоров и инвесторов (продавцов и покупателей), растет роль международных финансовых организаций в процессах аккумулирования ресурсов на покрытие убытков в случае реализации катастрофного сценария. Созданы успешные прецеденты выпусков облигаций катастроф группой государств. По итогам 30 лет были получены позитивные результаты, свидетельствующие о росте интереса к катастрофному финансированию и устойчивости спроса и предложения на такие инструменты даже в условиях спада и развития кризисной ситуации на мировых рынках. В то же время необходимо отметить, что облигации катастроф не являются панацеей и не могут рассматриваться как инструмент, несущий оАни только выгоды. В процессе функционирования рынка облигаций катастроф выявлено множество проблем, в том числе и морально-этических. Причем именно по инновационным разновидностям облигаций катастроф в силу малого опыта обращения и возникают проблемы. Так, в процессе выплат по пандемическим бондам ВБ (2017 г.) $)^{22}$ в 2020 г. возникли сложности - пострадавшие страны не смогли вовремя получить среАства на борьбу с пандемией в силу бюрократических барьеров и технических проблем ${ }^{23}$.

В России фактически сформировался запрос от государства и бизнеса, в том числе страхового сообщества, на создание сегмента катастрофного финансирования. Особая роль, по нашему мнению, в процессе формирования такого рынка Аолжна быть отведена институту развития в ^ице ВЭБ РФ в контексте его программ по устойчивому развитию24. Он может выступить спонсором такого рода бумаг. Банк России также проявляет серьезный интерес к вопросам оценки влияния климатических рисков на устойчивое развитие финансового сектора РФ, что нашло отражение в подготовке Аоклада Аля общественных консультаций в 2020 г. и ряде Аругих публикаций ${ }^{25}$. Также, несомненно, наработанная Банком России регулятивная база в части обращения инструментов Аля квалифицированных инвесторов может быть использована на рынке облигаций катастроф.

Широкое разнообразие финансовых инструментов в арсенале федеральных и региональных властей и развитие государственно-частного партнерства поможет сформировать гибкие механизмы покрытия убытков при наступлении стихийных бедствий. Так, наряду с инструментами традиционного страхования и перестрахования можно использовать обмигации катастроф и ILS. В то же время государственные Аолговые инструменты могут помочь справиться с фазой бедствий, а средства, привлеченные в «зеленые» облигации, будут способствовать адаптации к изменению климата и снижению риска катастроф.

Несомненно, в процессе адаптации необходимо постоянно расширять спектр охвата Аанных и совершенствовать методику регулирования, в том числе за счет расширения Аиапазонов использования инструментов катастрофного финансирования и их модификаций.

\footnotetext{
22 Эмиссия составила 320 млн Аом.. США. Права на выплаты имеют 76 стран МАР, поА выплаты подпадали случаи пандемии, вызванной вирусами: Influenza, coronaviruses, Filovirus, Lassa Fever, Rift Valley Fever and Crimean Congo Hemorrhagic Fever.

${ }^{23}$ World Bank abandons pandemic bond instrument after disastrous Covid-19 response. URL: https://www. brettonwoodsproject.org/2020/10/world-bank-abandons-pandemic-bond-instrument-after-disastrous-covid-19response/.

${ }^{24}$ Отчетность об устойчивом развитии / ВЭБ.РФ. URL:https://xn--90ab5f.xn--p1ai/investoram/otchetnost/ otchetnost-ob-ustoychivom-razvitii/.

${ }^{25}$ Влияние климатических рисков и устойчивое развитие финансового сектора РФ. АоклаА Аля общественных консультаций. Май 2020 г.
} 


\section{Список источников}

Володин С. Н., Мистрюков Ю. С. Облигации катастроф: анализ инструмента и возможности использования в России // Валютное регулирование. Валютный контроль. 2018. № 6. С. 52-57. URL: https://publications.hse.ru/ mirror/pubs/share/direct/221808885.

Огорелкова Н. В. Вопросы секьюритизации рисков природных катастроф в России // Вестник Омского университета. Серия “Экономика». 2016. № 3. С. 67-76. URL: https://cyberleninka.ru/article/n/voprosy-sekyuritizatsiiriskov-prirodnyh-katastrof-v-rossii.

Суняев А. С. Облигации на катастрофы как производный инвестиционный инструмент рынка перестрахования России // Научный альманах 2015 № 11-1 (13) Экономические науки 522. URL: https://doi.org/10.17117/ na.2015.11.01.522.

Токарева Е. А. Мировой опыт страхования рисков природных катастроф / Под реА. А. И. Цветковой. М.: Анкил, 2015. 88 c.

Федорова Е. П. Роль государства в решении проблем развития "зеленого" финансирования // Финансовый журнал. 2020. Т. 12. № 4. С. 37-51. URL: https://doi.org/10.31107/2075-1990-2020-4-37-51.

Хуторова Н. А. Управление рисками катастроф посреАством инновационных финансовых инструментов // Вестник Московского государственного университета леса - ^есной вестник. 2010. № 7. С. 119-123.

Хуторова Н. А. Перспективы развития сегмента катастрофного финансирования в контексте нарастания природных рисков и рисков пандемий / IV Российский экономический конгресс. T. XVIII. Тематическая конференция "Банки и финансовые рынки" (сборник материалов) / Составители С. А. Андрюшин, А. М. Карминский. М., 2020. С. $157-161$.

Яковлев И. А., Кабир ^. С. Механизм финансирования "зеленых" инвестиций как элемент национальной стратегии финансирования устойчивого развития // Финансовый журнал. 2018. № 3. С. 9-21.

Ayyub B. M., Pantelous A. A., Shao J. Towards Resilience to Catastrophic Events: Financing Liabilities via Catastrophe Risk Bonds / Economics of Community Disaster Resilience Workshop Proceedings. NIST Special Publication 1600, 2016. P. 101-112. URL: https://doi.org/10.6028/NIST.SP.1600.

Baca A., Jain A. Demystifying catastrophe bonds for debt managers / World Bank, 2018. URL: http://pubdocs. worldbank.org/en/555651528746619166/webinar-demystifyingcatastrophebondsfordebtmanagers2018presentation-abigailbacaandakinchanjain.pdf.

Bevere L., Ehrler A., Kumar V. et al. Natural catastrophes and man-made disasters in 2018: "secondary" perils on the frontline / Swiss Re Sigma. № 2. 2019. URL: https://www.swissre.com/dam/jcr:c37eb0e4-c0b9-4a9f-99543d0bb4339bfd/sigma2_2019_en.pdf.

Blanchet J. H., Lam H., Tang Q. et al. Mitigating Extreme Risk Through Securitization / Society of Actuaries, 2017. URL: https://www.soa.org/globalassets/assets/files/research/projects/2017-03-mitigating-risks-throughsecuritization.pdf.

Braun A. Pricing in the Primary Market for Cat Bonds: New Empirical Evidence // The Journal of Risk and Insurance. 2016. Vol. 83. Iss. 4. P. 811-847. URL: https://doi.org/10.1111/jori.12067.

Clark S. P., Dickson M., Neale F. R. Portfolio Diversification Effects of Catastrophe Bonds, 2016. URL: https:// dx.doi.org/10.2139/ssrn.2806432.

Cox S. H., Pedersen H. W. Catastrophe Risk Bonds // North American Actuarial Journal. 2000. Vol. 4. Iss. 4. URL: https://doi.org/10.1080/10920277.2000.10595938.

Cox S. H., Fairchild J. R., Pedersen H. W. Economic Aspects of Securitization of Risk. 2000 // ASTIN Bulletin: The Journal of the IAA. Vol. 30. No. 1. P. 157-193. URL: https://doi.org/10.2143/AST.30.1.504631.

Hagedorn D., Heigl C., Müllera F. et al. Choice of Triggers / The Handbook of Insurance. 2012. URL: https:// onlinelibrary.wiley.com/doi/abs/10.1002/9781119206545.ch4.

ILS Annual Report 2019. Alternative Capital: Strength Through Disruption / Aon Securities, 2019. URL: http://thoughtleadership.aonbenfield.com//Documents/20190905-ils-annual.pdf?utm_source=slipcase\&utm_ medium=affiliate\&utm_campaign=slipcase.

The MSCl Principles of Sustainable Investing / MSCl, 2020. URL: https://www.msci.com/documents/ 10199/16912162/MSCI-ESG-House-View-FINAL.pdf/63bba1a1-aecf-ba80-aa49-7910748ed942?t= 1579587918450.

\section{References}

Aon Securities (2019). ILS Annual Report Alternative Capital: Strength Through Disruption. Available at: http://thoughtleadership.aonbenfield.com//Documents/20190905-ils-annual.pdf?utm_source=slipcase\&utm_ medium=affiliate\&utm_campaign=slipcase.

Ayyub B.M., Pantelous A.A., Shao J. (2016). Towards Resilience to Catastrophic Events: Financing Liabilities via Catastrophe Risk Bonds, In Economics of Community Disaster Resilience Workshop Proceedings: NIST Special Publication 1600, pp. 101-112. Available at: https://doi.org/10.6028/NIST.SP.1600.

Baca A., Jain A. (2018). Demystifying catastrophe bonds for debt managers. World Bank. Available at: http:// pubdocs.worldbank.org/en/555651528746619166/webinar-demystifyingcatastrophebondsfordebtmanagers 2018-presentation-abigailbacaandakinchanjain.pdf. 
Braun A. (2016). Pricing in the Primary Market for Cat Bonds: New Empirical Evidence. The Journal of Risk and Insurance, vol. 83, iss. 4, pp. 811-847. Available at: https://doi.org/10.1111/jori.12067.

Blanchet J.H., Lam H., Tang Q. et al. (2017). Mitigating Extreme Risk Through Securitization. Society of Actuaries. Available at: https://www.soa.org/globalassets/assets/files/research/projects/2017-03-mitigating-risks-throughsecuritization.pdf.

Bevere L., Ehrler A., Kumar V. et al. (2019). Natural catastrophes and man-made disasters in 2018: "secondary" perils on the frontline. Swiss Re Institute, no 2. Available at: https://www.swissre.com/dam/jcr:c37eb0e4-c0b94a9f-9954-3d0bb4339bfd/sigma2_2019_en.pdf.

Cox S.H., Pedersen H.W. (2000). Catastrophe Risk Bonds. North American Actuarial Journal, vol. 4, iss. 4. Available at: https://doi.org/10.1080/10920277.2000.10595938.

Cox S.H., Fairchild J.R., Pedersen H.W. (2000). Economic Aspects of Securitization of Risk. ASTIN Bulletin: The Journal of the IAA, vol. 30, no. 1, pp. 157-193. Available at: https://doi.org/10.2143/AST.30.1.504631.

Clark S.P., Dickson M., Neale F.R. (2016). Portfolio Diversification Effects of Catastrophe Bonds. Available at: https://dx.doi.org/10.2139/ssrn.2806432.

Fedorova E.P. (2020). Role of the State in the Resolution of Green Finance Development Issues. Finansovyj žhurnal - Financial Journal, vol. 12, no. 4. pp. 37-51 (In Russ.). Available at: https://doi.org/10.31107/2075-19902020-4-37-51.

Khutorova N.A. (2010). Risk Management of the Disaster by Innovative Financial Instruments. Bulletin of the Moscow State Forest University - Forestry Bulletin, no. 7, pp. 119-123 (In Russ.).

Khutorova N.A. (2020). Prospects for the Catastrophic Financing Development in the Context of the Growing Natural and Pandemic Risks. IV Russian Economic Congress., vol. XVIII. Banks and Financial Markets Thematic Conference (collection of materials). Compiled by S.A. Andryushin, A.M. Karminsky, Moscow, pp. 157-161 (In Russ.).

MSCI (2020). The MSCI Principles of Sustainable Investing. Available at: https://www.msci.com/documents/ 10199/16912162/MSCI-ESG-House-View-FINAL.pdf/63bba1a1-aecf-ba80-aa49-7910748ed942?t= 1579587918450.

Ogorelkova N.V. (2016). Catastrophe Risks Securitization in Russia. Vestnik Omskogo universiteta. Seriya "Ekonomika" - Herald of Omsk University. Series "Economics", no. 3, pp. 67-76 (In Russ.). Available at: http:// journal.omeco.ru/ru/archive/doc/2016_03.pdf.

Sunyaev A.S. (2015). Catastrophe Bonds as a Derived Investment Tool of the Reinsurance Market. Nauchnyj al'manah - Scientific almanac, no. 11-1 (13) (In Russ.). Available at: https://doi.org/10.17117/na.2015.11.01.522.

Tokareva E.A. (2015). World Experience in Natural Disaster Risk Insurance. Ed. L.I. Tsvetkova. Moscow: Ankil Publ., 2015, 88 p. (In Russ.).

Yakovlev I.A., Kabir L.S. (2018). Green Investment Financing Mechanism as an Element of the National Strategy for Sustainable Development Financing. Finansovyj žhurnal - Financial Journal, no. 3, pp. 9-21 (In Russ.).

Volodin S.N., Mistryukov Yu.S. (2018). Cat Bonds: Instrument Analysis and Use Opportunities in Russia. Valyutnoe regulirovanie. Valyutnyi kontrol' - Currency Rregulation. Foreign Exchange Control, no. 6, pp. 52-57 (In Russ.). Available at: https://publications.hse.ru/mirror/pubs/share/direct/221808885.

\section{Информация об авторе}

Наталья Александровна Хуторова, кандидат экономических наук, Аоцент, Аоцент кафедры экономической безопасности Института права и национальной безопасности Российской академии народного хозяйства и государственной службы при Президенте РФ, г. Москва

\section{Information about the author}

Natalya A. Khutorova, Candidate of Economic Sciences, Associate Professor, Department of Economic Security, Institute of Law and National Security, Russian Presidential Academy of National Economy and Public Administration (RANEPA), Moscow

Статья поступила в редакцию 13.10.2020

ОАобрена после рецензирования 19.01.2021

Принята к публикации 15.02.2021

Article submitted Oct 13, 2020

Approved after reviewing Jan 19, 2021

Accepted for publication Feb 15, 2021 